performed amongst higher trainees at our tertiary-centre teaching hospital.

Results $100 \%$ response rate was obtained from 23 trainees. $43 \%$ and $60 \%$ felt confident in performing a brachial plexus block and lower limb block, respectively. 30\% felt confident performing regional anaesthesia for awake surgery whilst $17 \%$ reported sufficient opportunities in general training to develop competence in both upper and lower limb regional techniques. Conclusions Despite applications of regional anaesthesia becoming more prevalent, it currently remains a subspecialist skill. The mandate for regional anaesthesia proficiency in the new UK curriculum aims to address this disparity and improve equity of patient care. Our findings suggest there will need to be significant promotion of regional anaesthesia within training to enable universal competence.

\section{FEASIBILITY OF PRE-ANESTHETIC TELEMEDICINE CONSULTATION IN ELECTIVE ORTHOPEDIC SURGERY: EXPERIENCE DURING THE COVID-19 PANDEMIC}

${ }^{1} \mathrm{~F}$ Le Sache*, ${ }^{2} \mathrm{C}$ Naudin, ${ }^{2} \mathrm{M}$ Merzoug, ${ }^{1} \mathrm{M}$ Bucciero, ${ }^{1} \mathrm{D}$ Barouk, ${ }^{1} \mathrm{~S}$ Bloc. ${ }^{1} \mathrm{Clinique}$ Drouot Sport, Paris, France; ${ }^{2}$ Clinical Research Department, Neuilly-sur-Seine, France

\subsection{6/rapm-2021-ESRA.96}

Background and Aims Telemedicine is becoming more and more used for medical consultation. During the post-COVID19 period this mode was supported by the French Society of Anesthesia to reduce the risk of viral transmission $(1,2)$. The aim of this study was to determine the rate of successful telemedicine preoperative anesthesia consultation.

Methods This observational, single-center, prospective study, included 267 patients scheduled for elective orthopedic surgery. They were invited to choose either virtual (TeleMed-C) or face-to-face (Face-Face-C) anesthetic preoperative consultation. Every TeleMed-C was carried out through a dedicated website. The Patient Environment Quality Index (PEQI) during TeleMed-C was assessed. Patient satisfaction and opinion about TeleMed-C were assessed using a 5-point Likert scale. The use of a third-party facilitator was noted.

Results The success of TeleMed-C without cancellation or postponement of surgery was $89.5 \%$. A third-party facilitator was present in $46 \%$ of the patients over 65 yr. TeleMed-C happened in an adapted environment (98\%) which led to a high level of patient satisfaction (97\%) and a very high opinion (93\%).

Conclusions TeleMed-C is a preoperative anesthetic consultation method which could be widely highly selected by the patients, without increasing the risks of postponed or

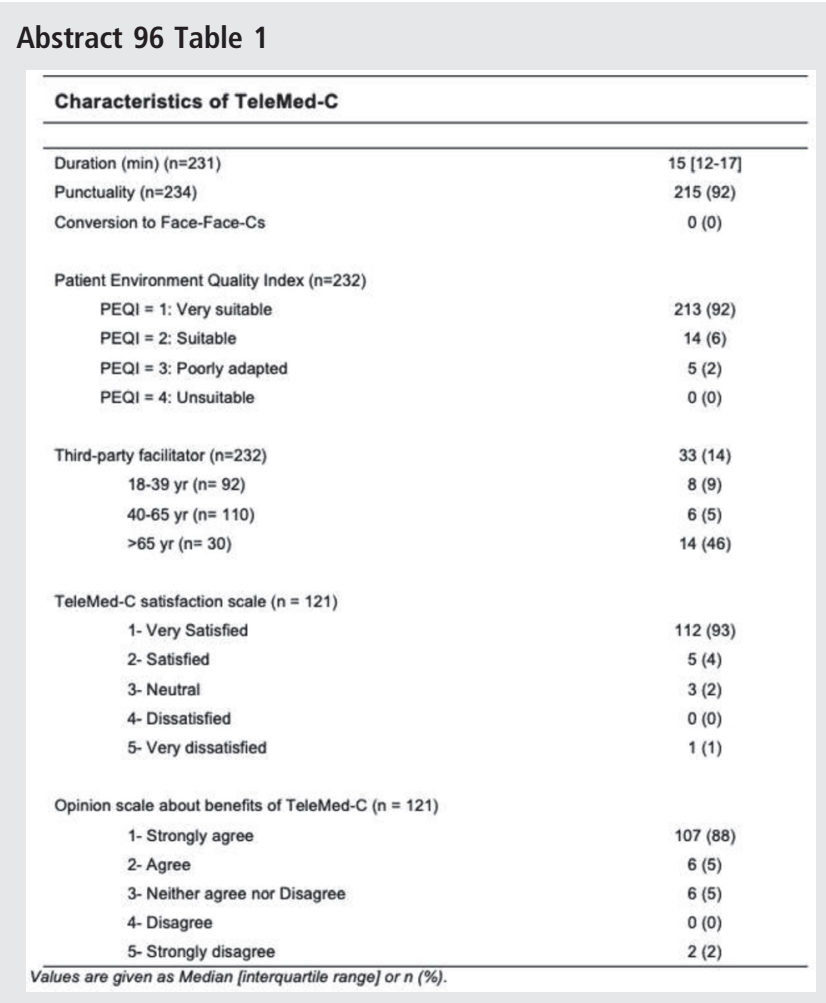

cancelled surgery. It should be considered as a valid procedure, and not only as an alternative to Face-Face-C.

\section{ABDOMINAL WALL BLOCKS FOR EMERGENCY ILEOSTOMY OPERATION IN A PATIENT WITH COVID-19 PNEUMONIA}

BB Güven, T Erturk, T Güner*, A Ersoy. Sultan Abdulhamidhan Sample and Training Hospital, Istanbul, Turkey

\subsection{6/rapm-2021-ESRA.97}

Background and Aims The anesthesia method to be administered during emergency surgical procedures for COVID-19 pneumonia patients carries great importance for both patient and surgical team. Regional blocks are generally used to ensure postoperative analgesia after abdominal surgery with general anesthesia. In this case, involving a patient receiving anticoagulant treatment due to COVID-19 pneumonia with planned emergency operation, the aim was to present the anesthesia management with rectus sheath(RS) and transversus

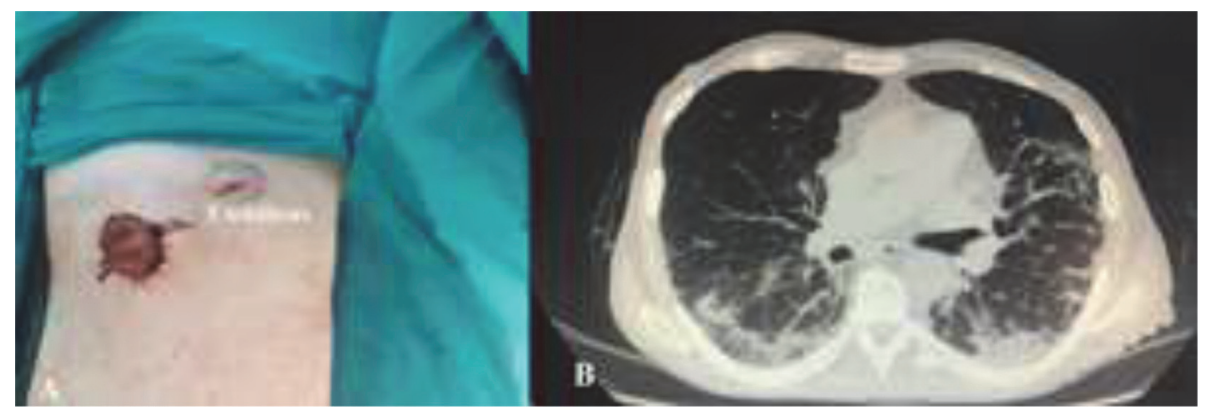

